Brit. Heart f., 1967, 29, 852.

\title{
Familial Dissecting Aortic Aneurysm
}

\author{
A Report of three Cases within two Generations
}

\author{
W. B. HANLEY^ ${ }^{\star}$ AND N. BENNETT JONES
}

From Whiston Hospital, Prescot, Lancs.

Dissecting aneurysm of the aorta is a relatively rare disorder, its true incidence being difficult to determine. Graham and Milne (1952), in a 25-year retrospective study of admissions to a Glasgow hospital, found it to occur once in every 9131 admissions. From a review of the published reports they found that the incidence at necropsy varied between $0 \cdot 1$ and $1 \cdot 1$ per cent.

In at least 80 per cent, the onset is sudden, leading to profound shock and death within a few hours. Survival is usually dependent on re-entry of the dissection into the aortic lumen. Jones and Langley (1946) estimated that re-entry occurred in 90 per cent of those surviving longer than 5 weeks. In surviving cases, the false channel may become established and sometimes endothelialized, producing the so-called double-barrelled aorta. The extent of the dissection varies but commonly extends for the full length of the aorta. Aortic incompetence frequently results from distortion or dilatation of the aortic valve ring (McKusick, 1960; Lewis, 1965). Estimates of the incidence of aortic incompetence in dissecting aneurysm vary from 20-56 per cent (O’Donovan, Osmundson, and Payne, 1964).

The main pathological processes predisposing to dissecting aneurysm are atheroma and cystic medionecrosis. The latter, first described by Erdheim (1930), is characterized by degeneration of elastic fibres and by the presence of cystic areas filled with metachromatically staining material. In a retrospective study of 29 cases, Graham and Milne (1952) found 16 with cystic medionecrosis and 13 with atheroma. On the other hand Braunstein (1963) found only 5 examples of cystic medionecrosis in 35 cases, the rest being classified

Received October 17, 1966.

* Present address: Southport General Infirmary, Southport, as arteriosclerotic. In both studies, the mean age of the cystic medionecrosis group was a little lower than that of the atheroma group. The site of the tear was usually in the ascending aorta in the cystic medionecrosis group but not infrequently in the abdominal aorta when the underlying lesion was atheroma.

Cystic medionecrosis is almost certainly not, ætiologically, a single disease entity. When occurring as an isolated pathological process, it is often known as Erdheim's disease (Erdheim, 1930), but a similar abnormality of the aorta occurs in the Marfan syndrome (Marfan, 1896). This is a hereditary condition transmitted as a dominant character, with the phenotype showing long thin extremities, arachnodactyly, excessive height, thoracic deformities, ectopia lentis, cardiovascular abnormalities, and a general weakness of ligaments, joint capsules, and fascia, which is responsible for a large group of manifestations including kyphoscoliosis, pes planus, recurrent joint dislocations, and herniæ. The Marfan syndrome is a leading cause of dissecting aneurysm in patients under 40 years of age and, with the control of rheumatic fever and syphilis, cystic medionecrosis is assuming greater importance as a cause of aortic incompetence (McKusick, 1960).

Dissecting aneurysm occurs with strikingly increased frequency during pregnancy and the puerperium. Approximately 50 per cent of the case reports of dissecting aneurysm occurring under 40 years of age have been in association with pregnancy (Schnitker and Bayer, 1944; Mandel, Evans, and Walsford, 1954). Some of them are examples of the Marfan syndrome (McKusick, 1960; Moore, 1965), but in many of the reports there is insufficient information to determine whether this syndrome was present.

Excluding the Marfan syndrome, hereditary 


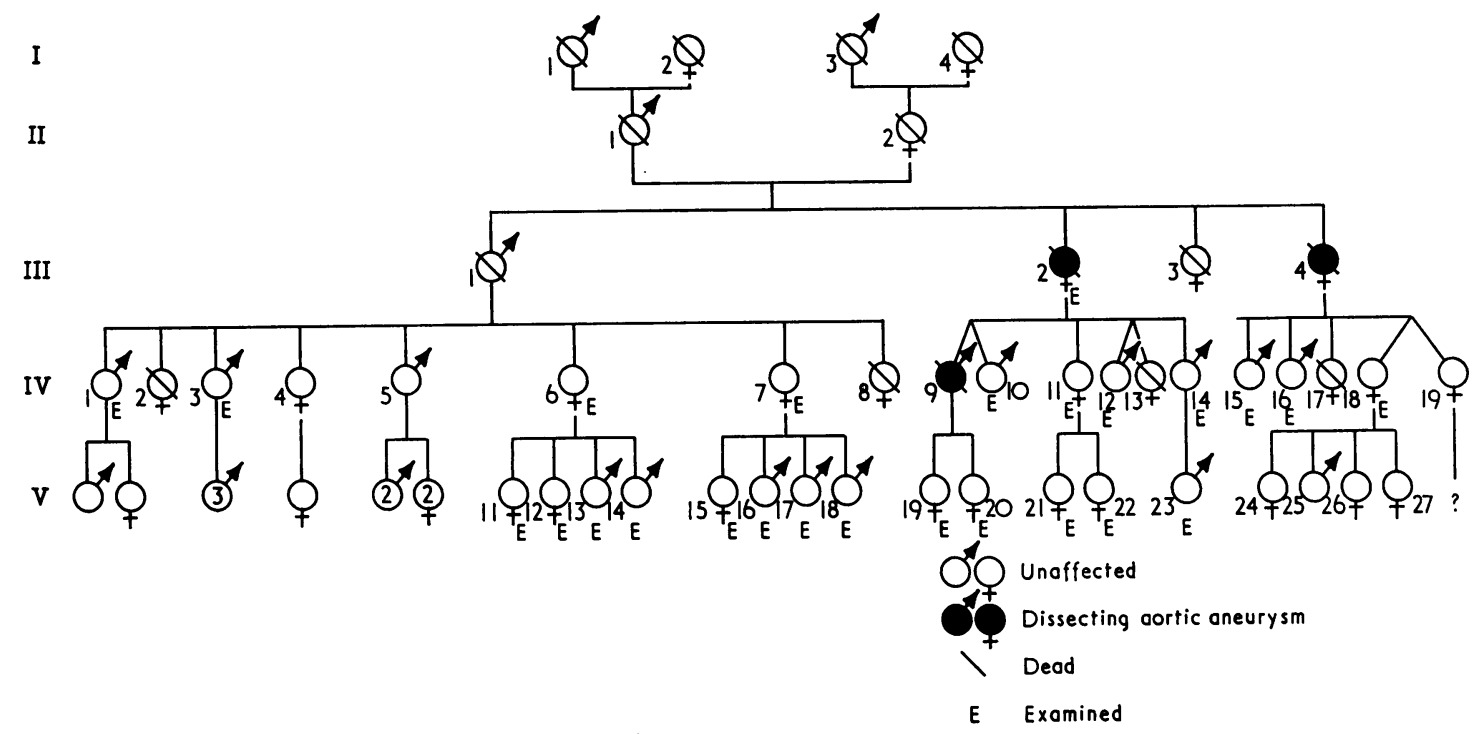

FIG. 1. Family pedigree.

factors do not appear important in the pathogenesis of dissecting aneurysm. While cystic medionecrosis resulting in dissecting aneurysm of the aorta has been reported in brothers (von Meyenburg, 1939; Graham and Milne, 1952), in father and son (Fleming and Helwig, 1941), and in mother and daughter (Griffiths, Hayhurst, and Whitehead, 1951), the clinical information provided in all these reports is too scanty to permit exclusion of the Marfan syndrome.

The following report describes three cases of dissecting aneurysm of the aorta within two generations of a family. Cystic medionecrosis was present in each case without any stigmata of the Marfan syndrome. The family pedigree is shown in Fig. 1.

\section{CASE REPORTS}

Case 1. M.A., a woman, born in 1907, had a history of rheumatic fever at the age of 10 years. Valvular damage was not recorded but subsequent dyspnoea on extra exertion had been attributed to rheumatic heart disease. An episode of slight hæmoptysis was investigated at a hospital out-patient department in 1953; nothing abnormal was found.

Four pregnancies, including twins, were uneventful. Recurrent epistaxis between 1956 and 1962 was treated by cauterization and nasal polypectomy. In 1957 a chest $x$-ray film revealed a normal cardiac outline, and in 1962, after hospital admission for epistaxis, examination of the cardiovascular system was recorded as normal.

In April 1963, at the age of 54, after running upstairs, she suddenly felt a severe choking pain in the throat with a feeling of imminent collapse. The pain radiated behind the sternum, through to the back, and into both arms and the right leg. These symptoms probably lasted a few hours but the patient had only a vague recollection of these early events. For the next few weeks there was a little weakness and numbness of the right arm and leg. During this time her general practitioner noted, for the first time, bruits suggestive of aortic and mitral valve disease. On resuming normal activities after about five weeks' bed-rest, the patient noticed breathlessness during housework which previously had produced no symptoms. Occasional dull retrosternal pain, with radiation to the back, continued both at rest and on exertion, and in May 1963 she was admitted again to hospital. Examination revealed an ill woman with herpes labialis and a mild pyrexia. The heart was enlarged and there was evidence suggestive of aortic and mitral valve incompetence; the blood pressure was $175 / 80 \mathrm{~mm} . \mathrm{Hg}$ and there was mild left ventricular failure. Electrocardiograms showed left ventricular hypertrophy but no evidence of myocardial infarction. Investigations failed to substantiate a tentative diagnosis of subacute bacterial endocarditis. Two weeks later there was a single half-hour attack of palpitations suggestive of paroxysmal tachycardia. She was discharged home after one month and managed fairly well for the ensuing year. Readmission because of congestive cardiac failure was necessary in June 1964, and she remained in varying degrees of cardiac decompensation until her death from chronic cardiac defeat in November 1964. Again the significant findings were a loud aortic diastolic murmur, and an apical pansystolic bruit radiating to the axilla. A loud systolic murmur was also noted over the carotid arteries. The pulse was regular 
and collapsing; the blood pressure was $150 / 60 \mathrm{~mm}$. $\mathrm{Hg}$. Pedal arterial pulses were normal. Serial electrocardiograms showed increasing left ventricular hypertrophy and "strain". During the last year of life, the body weight fell from 67 to about $51 \mathrm{~kg}$.

Necropsy. The body was that of a thin adult woman. Significant findings were confined to the cardiovascular system, except for a pulmonary infarct secondary to a pulmonary embolus involving half of the right lower lobe. The heart was grossly enlarged (632 g.), with biventricular dilatation and hypertrophy and dilatation of the atria. The aortic valve ring was dilated and distorted, but the valve cusps were soft and pliable. The mitral valve ring was dilated. The remaining valves were normal. The ostium of the left coronary artery was closed by the distortion of the aortic root, and there was infarction of the apical half of the anterior wall of the left ventricle. There was minimal atheroma of the coronary arteries. The aorta showed a "healed" dissecting aneurysm extending from its origin to the common iliac arteries. The false channel, which appeared endothelialized, opened into the aorta immediately above the cusps of the aortic valve. Histological examination of the aorta showed cystic medionecrosis; the lining of the false channel was, in fact, fibrous and not endothelial.

Case 2. S.B., born in 1903, a sister of Case 1, also had a history of rheumatic fever at the age of 10, the symptoms consisting of multiple joint pains and excessive sweating; the attack was said to have been mild. Four pregnancies between 1929 and 1937, and including two sets of twins, were normal. During one pregnancy her heart was considered to be "weak"; no details are known. She remained in good health until 1957 when she was investigated as an out-patient for attacks of supraventricular tachycardia. No underlying abnormality was found and the heart was of normal size with normal heart sounds and no bruits. In June 1960 she was admitted for investigation of a mild bilateral Raynaud's phenomenon. No abnormal findings were recorded though the blood pressure was $190 / 90 \mathrm{~mm}$. Hg. Again the heart was considered normal. A chest $x$-ray film and electrocardiogram showed no abnormality and other negative investigations included a full blood count, erythrocyte sedimentation rate, and urinalysis.

In June 1963, at the age of 59, she was admitted as an emergency, complaining of severe chest pain of several hours' duration. The pain had seemed to start during an attack of tachycardia. One week previously, while hanging out some washing, she had experienced a similar though milder pain which lasted several hours. The pain was retrosternal, vice-like, and severe, with radiation to the lower part of the chest, through to the back, and into the right arm. She also complained of mild exertional dyspnoea for the past 2 years and had experienced similar though much milder chest pain both on exertion and at rest for the preceding year. Attacks of tachycardia had continued intermittently but had been infrequent since 1960 . Recently they had been liable to cause mild retrosternal pain.
Examination revealed a pale-looking distressed woman. The pulse was regular, 50 a minute, and of good volume. The blood pressure was initially 85/30 but rose later to $120 / 70 \mathrm{~mm}$. $\mathrm{Hg}$. There was a soft aortic diastolic murmur and a systolic murmur at the apex and aortic area. A diagnosis was made of rheumatic aortic and possible mitral valve disease plus probable recent coronary thrombosis. Serial electrocardiograms showed no evidence of myocardial infarction but there was mild S-T segment depression in lead V4 and evidence of early left ventricular hypertrophy. One of the three SGOT estimations was slightly raised. Her general condition improved, though there was an intermittent left-sided pleuritic-like pain and a mild pyrexia for the first five days. A single episode of supraventricular tachycardia on the third in-patient day was successfully terminated with intravenous digoxin. She was discharged to convalesce at home after 2 weeks.

For about a year she remained in reasonable health but then increasing dyspnœa on mild exertion, often accompanied by central chest pain, orthopnœa, and general fatigue led to readmission in October 1964. Atrial fibrillation was now present and the heart was grossly enlarged with obvious left ventricular hypertrophy. There was a loud long aortic diastolic murmur and a harsh systolic bruit over the præcordium radiating into the neck; it was considerably louder over the left than over the right carotid artery. A faint rumbling middiastolic murmur at the apex was audible on occasions. The radial and brachial pulses in the right arm were of smaller volume than those in the left arm where they were collapsing. The blood pressure in the left arm was $170 / 60 \mathrm{~mm}$. Hg. A chest $x$-ray film showed cardiac enlargement with conspicuous left ventricular configuration; the aorta was prominent and a little unfolded. A diagnosis was made of rheumatic aortic and mitral valve disease, with the aortic lesion predominating and responsible for the episodes of myocardial ischæmic pain. The combination of mitral stenosis and atrial fibrillation was thought to have produced an embolus to the right brachial artery.

During the final nine months of life, congestive cardiac failure became increasingly resistant to therapy, and she finally died presenting the picture of cardiac cachexia, in July 1965. During the last 2 years there was loss of $19 \mathrm{~kg}$. in weight, the final weight being only $35 \mathrm{~kg}$. The right radial pulse was finally impalpable. Severe attacks of sharp, left-sided chest pain, sometimes aggravated by respiration, were prominent on occasions. No satisfactory cause for this pain was ever found. There was no further retrosternal pain. She had sometimes complained of cramp-like pains in both calves, suggestive of intermittent claudication. Details of the leg pulses were not recorded but the circulation in the feet was noted as good.

In November 1964, we learned of the post-mortem findings from the necropsy on her sister (Case 1). Review of the clinical picture in both cases revealed a striking similarity and it seemed highly likely that Case 2 was suffering also from the results of a "healed" dissecting aortic aneurysm which probably occurred in June 1963. 


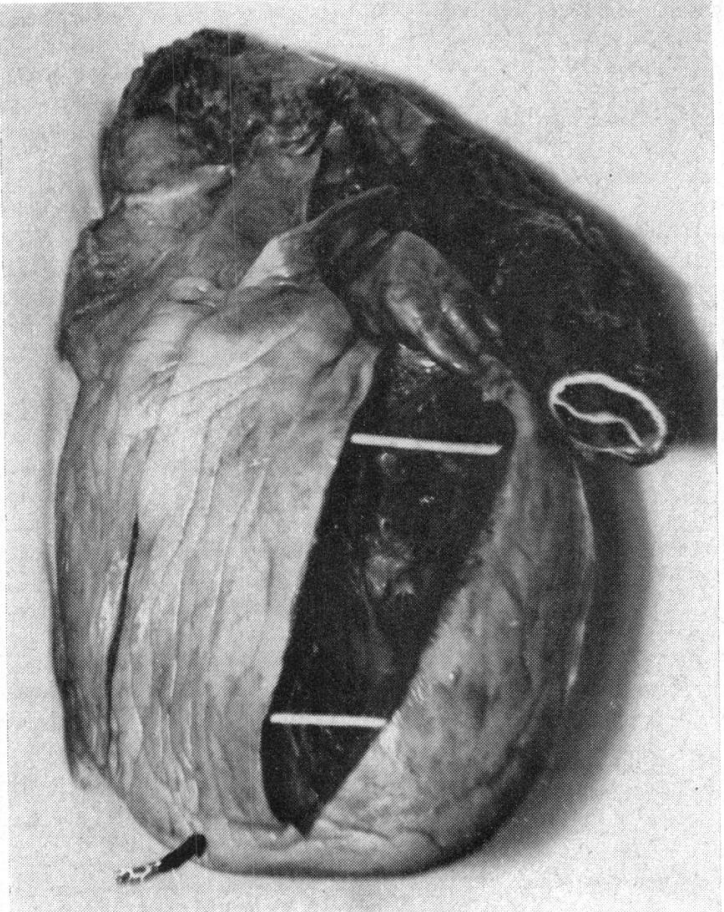

FIG. 2. The heart of Case 2, showing gross left ventricular hypertrophy and saccular dilatation of the ascending aorta. The double aortic channel is clearly shown at the severed end.

The false channel lies anterior to the true aortic lumen.

Further examination of Case 2 revealed no evidence of Marfan's syndrome, though the patient was extremely thin with a dorsal kyphosis. At this stage of her illness her height was $157 \mathrm{~cm}$. and the lower segment (pubis to heel) was $82 \mathrm{~cm}$. There was no arachnodactyly. The metacarpal (Sinclair, Kitchin, and Turner, 1960) and phalangeal (Parish, 1960) indices were well within normal (7.84 and 4.56, respectively). The palate and ligamentum patellæ were unremarkable, and slit-lamp examination of the eyes revealed no evidence of lens dislocation. There were no herniæ or varicose veins. It was still impossible to detect evidence of aortic aneurysm in the chest $x$-ray fllms of either Case 1 or Case 2, though both showed moderate aortic unfolding and cardiac enlargement.

Necropsy. Apart from the effects of prolonged congestive cardiac failure, the abnormal findings were confined to the cardiovascular system. The heart was grossly enlarged $(650 \mathrm{~g}$.) with considerable left ventricular hypertrophy and biventricular and atrial dilatation. Externally the ascending aorta was a little dilated and prominent (Fig. 2). There was a "healed" dissection of the aorta throughout its length, producing the socalled double-barrelled effect. The two channels were of equal size and apparently lined by endothelium. The

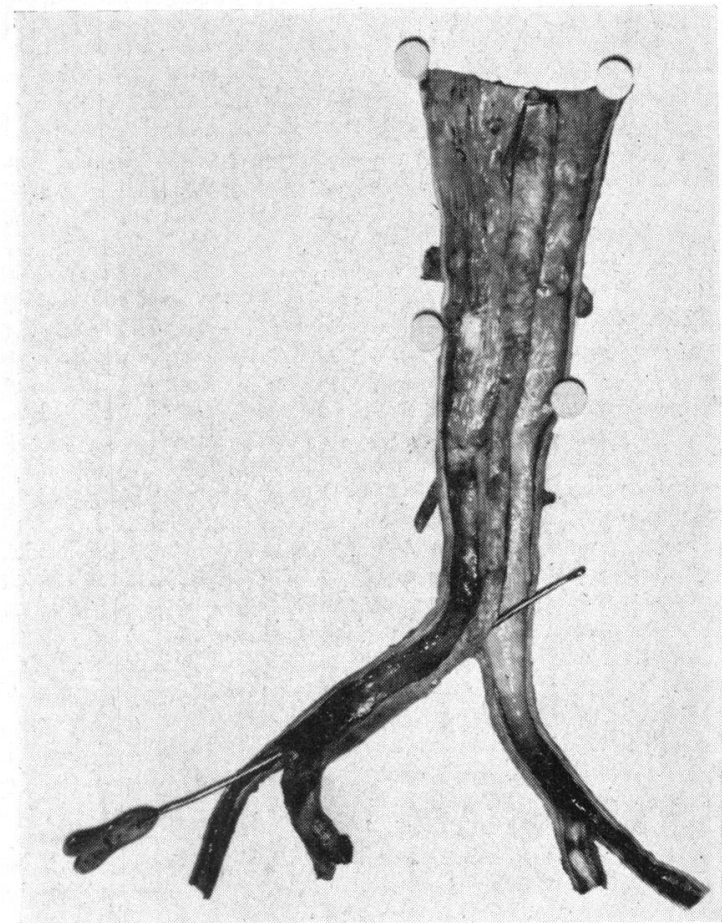

FIG. 3.-Distal aorta and iliac arteries of Case 2, showing the termination of the dissection at the bifurcation of the right common iliac artery. Most of the antero-lateral wall of each aortic channel has been cut away leaving the dividing septum intact. The true aortic lumen is on the left.

true aortic lumen was revealed only by the presence of a little atheroma. Fig. 3 shows the termination of the dissection at the bifurcation of the aorta. The proximal $15 \mathrm{~cm}$. of aorta were further studied by cutting away strips of the anterior and posterior walls, thus following the two aortic channels proximally, towards the left ventricle. The anterior channel was the false one, ending blindly in a considerably dilated sac at the aortic root (Fig. 4). There was an oval communication with the true aorta about $1.25 \mathrm{~cm}$. above the aortic valve. Its long axis was about $2.5 \mathrm{~cm}$. long and lay transversely; the edges were smooth and rolled (Fig. 4). The innominate artery arose from the false channel, and at its origin was largely occluded by both old and recent thrombus. Both the left common carotid and the left subclavian arteries arose from the true aortic lumen, and both were considerably narrowed at their origins by distortion. The aortic valves were normal and, surprisingly in view of the undoubted incompetence, the aortic valve ring was not dilated. The sinuses of Valsalva were larger than normal. The ostia of the coronary arteries were patent and there was no significant atheroma. The mitral, tricuspid, and pulmonary valves were normal.

Case 3. W.J.B., a son of Case 2 and a nephew of 


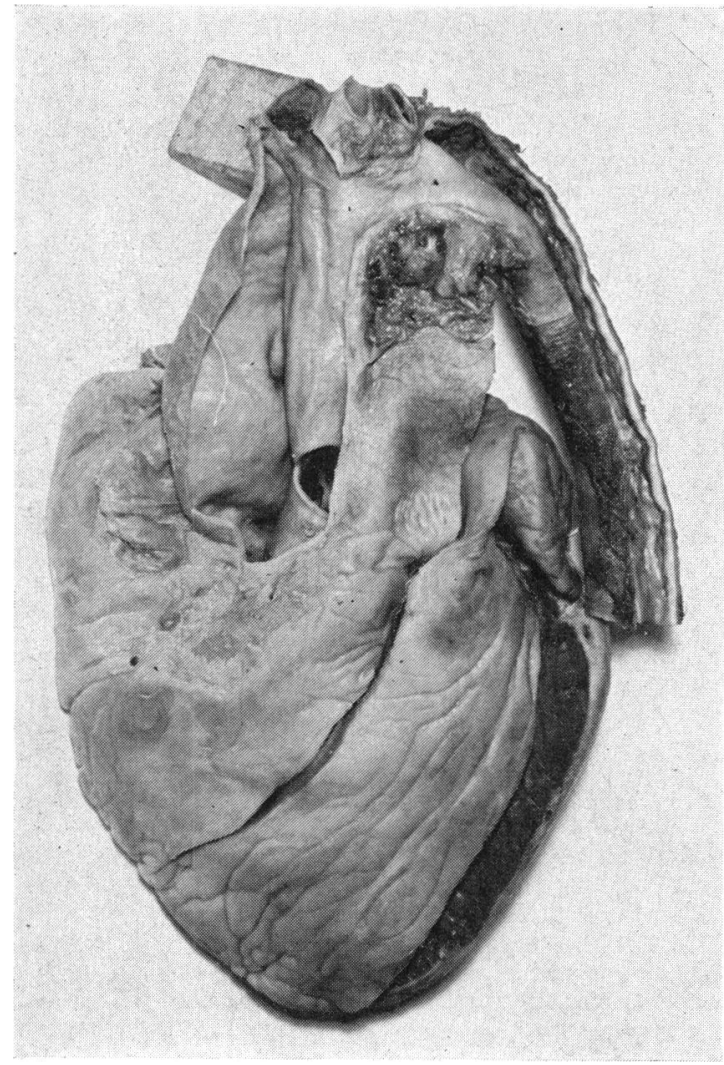

FIG. 4.-Heart of Case 2, with the anterior wall of the false aortic channel removed. The communication with the true aortic lumen, which lies behind it, is clearly shown at the aortic root. The innominate artery, its origin partially occluded by thrombus, arises from the false channel, and the left common carotid and the left subclavian arteries arise from the true aorta.

Case 1 (see pedigree, Fig. 1), was born in 1928. A lorry driver, and accustomed to hard work, he had been symptom free with no significant illnesses until a few days before his death in $\mathbf{1 9 5 8}$ at the age of 30 . One year previously a routine insurance medical examination had revealed no abnormality. His terminal illness began with mild influenzal symptoms. A few days later, while sitting at home, he felt worse and decided to go to bed. At the top of the stairs he developed a severe crushing retrosternal pain radiating to both arms and the back. He was admitted to hospital in a shocked condition and died a few hours later before an electrocardiogram could be taken; a provisional diagnosis of coronary thrombosis had been made. Details of stature were not recorded but from a photograph, and from questioning his wife and other relatives, there is no doubt that he was a broad, thick-set person, weighing $89 \mathrm{~kg}$., and approximately $167 \mathrm{~cm}$. in height. Reading glasses had been used for about one year before death, but otherwise his eyesight was considered normal.
Necropsy. The body was that of a well-built, wellnourished man. Abnormal findings were confined to the cardiovascular system except for pulmonary congestion and a horseshoe kidney. The heart was enlarged (575 g.) due to left ventricular hypertrophy. The heart valves and coronary arteries were normal. There was a recent dissecting aneurysm of the aorta involving the ascending portion, the arch, and the beginning of the descending portion. The aneurysm communicated with the aortic lumen by a tear at the site of a small patch of atheroma at the beginning of the descending aorta. So much blood had entered the sac that the lumen of the aortic arch was almost completely occluded. The pericardium was normal. Histological examination of the aorta revealed extensive cystic medionecrosis.

Other Family Members. It has been possible to question and examine 24 close relatives of the above cases, for evidence of cardiovascular abnormality; none has been found. A son of Case 2 (pedigree IV.14) had an attack of severe upper abdominal pain lasting about 6 hours in 1964. The pain did not radiate and no cause was discovered. Examination of this man revealed no abnormality and the pain has not recurred. Features excluded in each of the 24 relatives examined included the Marfan habitus, abnormal upper segment-lower segment ratio, arachnodactyly (as assessed clinically and by means of the metacarpal and phalangeal indices), arched palate, ectopia lentis (slit-lamp examination), and abnormally long ligamentum patellæ. Their chest $x$-ray films and electrocardiograms were also normal. Regarding family members not examined, clinical data pertaining to height, weight, habitus, eyesight, and general health were obtained by questioning close relatives. In particular, the parents of Cases 1 and 2 appear to have been normal. The mother died, aged 65, of cancer, and the father was killed in the First World War, at the age of 39 years.

\section{Discussion}

Post-mortem findings in Cases 1 and 2 exclude rheumatic valvular disease, and there is no doubt that the cardiovascular abnormalities in both cases were due entirely to the effects of the dissecting aneurysm which had occurred probably 19 and 25 months, respectively, before death. In Case 1, dilatation and distortion of the aortic valve ring caused severe incompetence and secondary functional mitral valve incompetence. In Case 2, there was no aortic valve abnormality and the aortic ring was not dilated. In life, however, there was undeniable aortic valve incompetence, and it must be assumed that it was due to distortion of the valve ring by the saccular proximal end of the dissecting aneurysm. The soft mitral diastolic murmur noted on occasions was almost certainly of the "Austin Flint" variety. 
The occurrence within two generations of three cases of dissecting aneurysm strongly suggests the presence of an aortic weakness due to a hereditary disease process. In a disease as rare as dissecting aneurysm it appears reasonable to exclude coincidence as the explanation, but it is just conceivable that environmental factors were responsible in this family. For example, it is known that immature rats fed a sweet-pea seed diet can develop a Marfanlike picture, with skeletal changes and dissecting aneurysm (Ponseti and Baird, 1952). This abnormality is induced more easily in male rats, and its incidence and severity are increased by the concurrent administration of androgens (Wajda, Lehr, and Krukowski, 1957). There is, however, no evidence to suggest that the dietary habits of the family under study were in any way different from those of the surrounding population. Except for the mother of Cases 1 and 2, who was of Irish descent, the whole family were of South-West Lancashire stock.

It is, therefore, likely that the occurrence of dissecting aneurysm in the above three cases was due to an underlying hereditary disease. In each case cystic medionecrosis of the aorta was the pathological abnormality; this is found both in Marfan's syndrome and in so-called idiopathic Erdheim's disease, the diagnosis of which is, for the present, a diagnosis by exclusion. Evidence of the Marfan syndrome in the above family has not been found. In particular, no case of ectopia lentis or arachnodactyly has been uncovered in the immediate family members. McKusick (1960) considers that ectopia lentis, while not essential to the diagnosis, is to be found on careful slit-lamp examination, in the majority of cases. Even when absent, it is likely to be found in other family members. While Cases 1 and 3 were not examined specifically for the Marfan syndrome, descriptions of their stature and body build from relatives and study of photographs, have not revealed any stigmata; on the contrary, Case 3 was of only moderate height, broad, and over $89 \mathrm{~kg}$. in weight.

While skeletal abnormalities in Marfan's syndrome often are prominent, there is considerable overlap with normal. The diagnosis may be difficult particularly when the Marfan gene is superimposed on the genetic milieu of a pyknic stock. Assessment of certain skeletal proportions is often more helpful than actual height. Of these, McKusick (1960) feels that the ratio of upper segment to lower segment is at least as reliable as any. The lower segment is the distance from the top of the symphysis pubis to the floor and the upper segment is derived by subtracting this value from the over-all height. The ratio varies during growth and may be in- fluenced by sex and race. From the data provided by McKusick (1960) it is possible to evaluate the upper-lower segment ratios of suspect cases. He considers the normal white adult ratio to be approximately 0.93 and, in the Marfan syndrome, about 0.85 . Graphs are given for the ratios in children.

In none of the relatives studied (Fig. 1) was the ratio even remotely abnormal. In Case 2 where there was a considerable kyphosis which would lower the ratio, the figure is still 0.908. Likewise, attempts have been made to define arachnodactyly by means of certain hand measurements. The metacarpal index (Sinclair et al., 1960) is the average of the ratios of length to width at the mid-point for each of the four metacarpals of the right hand (excluding the thumb). From a study of 100 normal adults the index was found to range from 5.4-7.9 (80\% in range $7 \cdot 0-7 \cdot 9$ ), and in 20 Marfan cases, $8 \cdot 4-10 \cdot 4(70 \%$ in $8 \cdot 4-9 \cdot 4$ range). Eldridge (1964) concluded that the metacarpal index was a more reliable distinguishing feature of Marfan's syndrome than the upper-lower segment ratio. Parish (1960, 1966) studied both the metacarpal index and a phalangeal index, a similar type ratio derived from measurements of the proximal phalanx of the right ring finger. For the right metacarpal index in man, the range was 5.9-8.1 (mean 6.86) and in women 6.3-8.9 (mean 7.6). For the phalangeal index the values were $3 \cdot 6-4 \cdot 7$ (mean $4 \cdot 1$ ) for men, and 4.1-5.4 (mean 4.65) for women. Both in Case 2 and in the relatives, the metacarpal and phalangeal indices are well within the normal range.

There is, therefore, no support for the possibility that the dissecting aneurysms in the above three cases were due to each possessing the Marfan gene. It is concluded that these cases supply evidence that Erdheim's cystic medionecrosis may occur as a hereditary condition. The pattern of inheritance in this family suggests autosomal dominant transmission. The condition has been described previously in brothers (von Meyenburg, 1939; Graham and Milne, 1952), in father and son (Fleming and Helwig, 1941), and in mother and daughter (Griffiths et al., 1951) but, as McKusick (1960) points out, in none are sufficient data given to exclude the Marfan syndrome.

Attacks of paroxysmal tachycardia probably occurred in Cases 1 and 2. While this condition has been described in Marfan's syndrome (Sinclair et al., 1960), it is nevertheless encountered frequently in cardiac disease and its occurrence in the above cases does not seem important diagnostically. The finding of a horseshoe kidney malformation in Case 3 can be viewed in the same light, though again, congenital abnormalities are reported in the Marfan syndrome (McKusick, 1960; Sinclair et al., 1960). 
In view of the frequency of dissecting aneurysm in pregnancy (Schnitker and Bayer, 1944; Mandel et al., 1954), it is perhaps remarkable that Cases 1 and 2 each had four uneventful pregnancies including one and two sets of twins, respectively.

\section{SUMMARY}

Described are two sisters in their sixth decade and a son of one of them, each of whom died from dissecting aneurysm of the aorta. The son died within hours but both sisters survived for some 18 months, their clinical picture being identical and closely mimicking rheumatic valvular heart disease. Necropsy findings are detailed for the three cases. Aortic cystic medionecrosis was present in each. It is suggested that a hereditary factor with autosomal dominant transmission is responsible for idiopathic aortic cystic medionecrosis as well as for the Marfan syndrome, the stigmata of which were not present in the cases described, nor in other family members.

Our grateful thanks go to Mr. J. M. Brodrick, consultant ophthalmic surgeon, for the slit-lamp examinations; to Drs. C. W. R. Roseby, P. Hurst, and A. G. Porterfield, general practitioners to the patients and relatives studied; to Drs. G. M. S. Ryan and G. Manson for allowing access to their hospital case notes; to Dr. Woodcock, pathologist, and to Dr. G. Sechiari, for drawing our attention to Case 1. Dr. V. A. McKusick, Division of Medical Genetics, Johns Hopkins Hospital, Baltimore, very kindly read the manuscript.

\section{REFERENCES}

Braunstein, H. (1963). Pathogenesis of dissecting aneurysm. Circulation, 28, 1071.

Eldridge, R. (1964). The metacarpal index. A useful aid in the diagnosis of the Marfan syndrome. Arch. intern. Med., 113, 248.
Erdheim, J. (1930). Medionecrosis aortæ idiopathica cystica. Virchows Arch. path. Anat., 276, 187.

Fleming, J. W., and Helwig, F. C. (1941). Medionecrosis aortæ ideopathica cystica with spontaneous rupture. Report of 3 cases with necropsies. f. Mo. med. Ass., 38, 86.

Graham, J. G., and Milne, J. A. (1952). Dissecting aneurysm of the aorta; a review of 29 cases. Glas. med.F., 33, 320.

Griffiths, G. J., Hayhurst, A. P., and Whitehead, R. (1951). Dissecting aneurysm of the aorta in mother and child. Brit. Heart f., 13, 364.

Jones, A. M., and Langley, F. A. (1946). Chronic dissecting aneurysms. Brit. Heart f., 8, 191.

Lewis, M. G. (1965). Idiopathic medionecrosis causing aortic incompetence. Brit. med. F., 1, 1478.

Mandel, W., Evans, E. W., and Walsford, R. L. (1954). Dissecting aortic aneurysm during pregnancy. New Engl. F. Med., 251, 1059.

Marfan, A. B. (1896). Un cas de déformation congenitale des quatre membres plus prononcée aux extrémités characterisée par l'allongement de os avec un certain degré,", d'amincissement. Bull. Mém. Soc. Méd. Hôp. Paris, 13, 220.

McKusick, V. A. (1960). Heritable Disorders of Connective Tissue, 2nd ed., pp. 42-134. Mosby, St. Louis.

von Meyenburg, H. (1939). Ueber spontane Aortenruptur bei zwei Brüdern. Schweiz. med. Wschr., 69, 976.

Moore, H. C. (1965). Marfan syndrome, dissecting aneurysm of the aorta, and pregnancy. F. clin. Path., 18, 277.

O'Donovan, T. P. B., Osmundson, P. J., and Payne, W. S. (1964). Painless dissecting aneurysm of the aorta. Report of a case. Circulation, 29, 782.

Parish, J. G. (1960). Heritable disorders of connective tissue. Skeletal syndromes associated with arachnodactyly. Proc. roy. Soc. Med., 53, 515.

- (1966). Radiographic measurements of the skeletal structure of the normal hand. Brit. F. Radiol., 39, 52.

Ponseti, I. V., and Baird, W. A. (1952). Scoliosis and dissecting aneurysm of the aorta in rats fed with Lathyrus odoratus seeds. Amer. F. Path., 28, 1059.

Schnitker, M. A., and Bayer, C. A. (1944). Dissecting aneurysm of the aorta in young individuals, particularly in association with pregnancy, with report of a case. Ann. intern. Med., 20, 486.

Sinclair, R. J. G., Kitchin, A. H., and Turner, R. W. D. (1960). The Marfan syndrome. Quart. F. Med., 29, 19.

Wajda, I., Lehr, D., and Krukowski, M. (1957). Sex differences in aortic rupture induced by Lathyrus odoratus in immature rats. Fed. Proc., 16, 343. 